\title{
Article \\ NAD(H) Regulates the Permeability Transition Pore in Mitochondria through an External Site
}

\author{
Ekaterina Kharechkina, Anna Nikiforova and Alexey Kruglov *(D)
}

Citation: Kharechkina, E.;

Nikiforova, A.; Kruglov, A. NAD(H) Regulates the Permeability Transition Pore in Mitochondria through an External Site. Int. J. Mol. Sci. 2021, 22, 8560. https://doi.org/10.3390/ ijms22168560

Academic Editors: Anthony Lemarié and Vito De Pinto

Received: 9 July 2021

Accepted: 5 August 2021

Published: 9 August 2021

Publisher's Note: MDPI stays neutral with regard to jurisdictional claims in published maps and institutional affiliations.

Copyright: (c) 2021 by the authors. Licensee MDPI, Basel, Switzerland. This article is an open access article distributed under the terms and conditions of the Creative Commons Attribution (CC BY) license (https:// creativecommons.org/licenses/by/ $4.0 /)$
Institute of Theoretical and Experimental Biophysics, Russian Academy of Sciences, 142290 Pushchino, Russia; katya.kypri@gmail.com (E.K.); nikiforanna@yandex.ru (A.N.)

* Correspondence: krugalex@rambler.ru; Tel.: +7-4967739107

\begin{abstract}
The opening of the permeability transition pore (mPTP) in mitochondria initiates cell death in numerous diseases. The regulation of $\mathrm{mPTP}$ by $\mathrm{NAD}(\mathrm{H})$ in the mitochondrial matrix is well established; however, the role of extramitochondrial (cytosolic) $\mathrm{NAD}(\mathrm{H})$ is still unclear. We studied the effect of added NADH and $\mathrm{NAD}^{+}$on: (1) the $\mathrm{Ca}^{2+}$-retention capacity $(\mathrm{CRC})$ of isolated rat liver, heart, and brain mitochondria; (2) the $\mathrm{Ca}^{2+}$-dependent mitochondrial swelling in media whose particles can $(\mathrm{KCl})$ or cannot (sucrose) be extruded from the matrix by mitochondrial carriers; (3) the $\mathrm{Ca}^{2+}$-dependent mitochondrial depolarization and the release of entrapped calcein from mitochondria of permeabilized hepatocytes; and (4) the $\mathrm{Ca}^{2+}$-dependent mitochondrial depolarization and subsequent repolarization. $\mathrm{NADH}$ and $\mathrm{NAD}^{+}$increased the CRC of liver, heart, and brain mitochondria 1.5-2.5 times, insignificantly affecting the rate of $\mathrm{Ca}^{2+}$-uptake and the free $\mathrm{Ca}^{2+}$ concentration in the medium. $\mathrm{NAD}(\mathrm{H})$ suppressed the $\mathrm{Ca}^{2+}$-dependent mitochondrial swelling both in $\mathrm{KCl}$ - and sucrose-based media but did not induce the contraction and repolarization of swollen mitochondria. By contrast, EGTA caused mitochondrial repolarization in both media and the contraction in $\mathrm{KCl}$-based medium only. $\mathrm{NAD}(\mathrm{H})$ delayed the $\mathrm{Ca}^{2+}$-dependent depolarization and the release of calcein from individual mitochondria in hepatocytes. These data unambiguously demonstrate the existence of an external NAD(H)-dependent site of mPTP regulation.
\end{abstract}

Keywords: permeability transition pore; $\mathrm{NADH}$; $\mathrm{NAD}^{+}$; pore closure; calcium retention capacity; external regulatory site; cytosolic

\section{Introduction}

Nicotinamide adenine dinucleotide $(\mathrm{NAD}(\mathrm{H}))$ plays a pivotal role in the regulation of a huge number of cellular processes. In addition to the participation in the transformation of energy, $\mathrm{NAD}^{+}$, and its derivatives regulate the activity and expression of numerous enzymes involved in cellular and mitochondrial metabolism, muscle contraction, DNA repair, antioxidant protection, biogenesis, cell differentiation and aging, autophagy, and inflammatory response [1-6]. Moreover, $\mathrm{NAD}(\mathrm{H})$ is one of the most potent endogenous regulators of the $\mathrm{Ca}^{2+}$-dependent mitochondrial permeability transition pore (mPTP) whose opening triggers cell death in various pathologies [7]. Earlier, it was shown that NADH at millimolar concentrations reversed the opening of MPTP and increased the capability of mitochondria to accumulate and retain $\mathrm{Ca}^{2+}$, acting on an unidentified regulatory site in the mitochondrial matrix [8-11]. NAD ${ }^{+}$also induced the mPTP closure, but about 10 times less effective than NADH [8,9]. At the same time, the oxidation of endogenous NADH was associated with a decrease in the ability of mitochondria to accumulate and retain $\mathrm{Ca}^{2+}$, but not with the opening of mPTP per se $[10,11]$. The ability of added NAD(H) to close the opened mPTP was inhibited by added $\mathrm{NADP}(\mathrm{H})$, which was interpreted as a competition for the allosteric regulatory site [9]. In addition, the $\mathrm{NAD}^{+}$-dependent deacetylation of various proteins, in particular MnSOD, by SIRT3 [12,13] increased the resistance of mitochondria of aged rats to $\mathrm{mPTP}$ opening by $\mathrm{Ca}^{2+}[4]$. Besides, the authors 
claimed that SIRT3 deacetylates the important mPTP promoter cyclophylin D; however, whether this affects the cyclophylin D activity or mPTP opening is currently unclear.

Until recently, there was little information about the regulation of MPTP opening by external (i.e., acting from the cytosolic side) $\mathrm{NAD}(\mathrm{H})$. On the one hand, it was established that the poly (ADP-ribose) polymerase-mediated degradation of cytosolic $\mathrm{NAD}^{+}$is one of the main causes of cell death during ischemia/reperfusion [14-17]. Furthermore, increased cytosolic NADH/NAD ${ }^{+}$ratios can be a signal for proliferation [18,19]. On the other hand, it was shown that external NADH can stimulate the mPTP opening in the presence of redox-cycling compounds such as menadione and lucigenin. The effect was mediated by $\mathrm{NADH}$-dependent cytochrome $b_{5}$ oxidoreductase 3 in the outer mitochondrial membrane $(\mathrm{OMM})$, which reduced the redox cyclers to thiol-reactive radicals and thus promoted the mPTP opening [20-22].

Recently, we have found that $\operatorname{NAD}(\mathrm{H})$ added at physiological concentrations to the incubation medium (cytosolic side of mitochondrial membranes) potently suppresses the opening of $\mathrm{mPTP}$ in the mitochondria of differentiated cells and enhances the protective effect of adenine nucleotides and cyclosporin A (CsA) [23]. Since NAD(H) cannot penetrate through the intact inner mitochondrial membrane (IMM) [24,25], these data could indicate the existence of a $\mathrm{NAD}(\mathrm{H})$-dependent site of $\mathrm{mPTP}$ regulation in the OMM or the intermembrane space (IMS) of mitochondria. However, it is well known that mPTP opening can be reversible $[9,26-29]$, while exogenous NADH can penetrate through the opened mPTP and interact with matrix enzymes [30]. According to the earlier data of Haworth and Hunter, it was exogenous $\mathrm{NAD}(\mathrm{H})$ that caused the closure of the opened $\mathrm{mPTP}$ by acting on the allosteric regulatory site in the matrix [8,9]. Therefore, when registering a decrease in the optical density in mitochondrial suspension (which reflects the swelling of organelles), it is impossible to say, unambiguously, whether $\mathrm{NAD}(\mathrm{H})$ suppresses the opening or induces the closing of $\mathrm{MPTP}$ in each individual mitochondrion.

In the present work, we studied in detail the localization of the site of $\mathrm{MPTP}$ regulation by external $\mathrm{NAD}(\mathrm{H})$. We investigated the effects of external $\mathrm{NAD}(\mathrm{H})$ on the maximum CRC of mitochondria isolated from various organs, the swelling, and contraction of mitochondria in incubation media containing solutes transported and not transported by carriers of the $\mathrm{IMM}$, and the $\mathrm{Ca}^{2+}$-dependent dissipation of the mitochondrial membrane potential $(\Delta \Psi \mathrm{m})$ and the release of 620-Da fluorescent dye from individual mitochondria of hepatocytes permeabilized with digitonin. The data obtained unambiguously indicate that the site of the regulation of mPTP by cytosolic $\mathrm{NAD}(\mathrm{H})$ is located either at the OMM, or the IMS, or the outer surface of the IMM.

\section{Results}

\section{1. $\mathrm{NAD}(\mathrm{H})$ Increases the $\mathrm{Ca}^{2+}$-Retention Capacity of Liver, Heart, and Brain Mitochondria}

The release of $\mathrm{Ca}^{2+}$ from mitochondria can occur much earlier than the complete opening of mPTP and entry into the matrix of low-molecular-weight solutes $\left(\mathrm{K}^{+}, \mathrm{Cl}^{-}\right.$, sucrose, mannitol, etc.), which cause the swelling of mitochondria [26-29]. The molecular weight of $\mathrm{NAD}(\mathrm{H})$ is significantly greater than the molecular weight of the hydrated forms of all the compounds mentioned above. Therefore, we first studied the effect of NADH and $\mathrm{NAD}^{+}$on the maximum CRC of RLM, RHM, and RBM. As it follows from Figure 1, 1 mM NADH increased the CRC of RLM (A), RHM (B), and RBM (C) 2.1, 2.6, and 1.5 times, respectively, while $1 \mathrm{mM} \mathrm{NAD}^{+}$was slightly less effective. The curves of $\mathrm{Ca}^{2+}$ uptake demonstrate that the protective effect of $\mathrm{NADH}$ was manifested before the massive release of accumulated $\mathrm{Ca}^{2+}$. Hence, $\mathrm{NAD}(\mathrm{H})$, presumably, protected mitochondria even before a significant increase in the permeability of the IMM. 

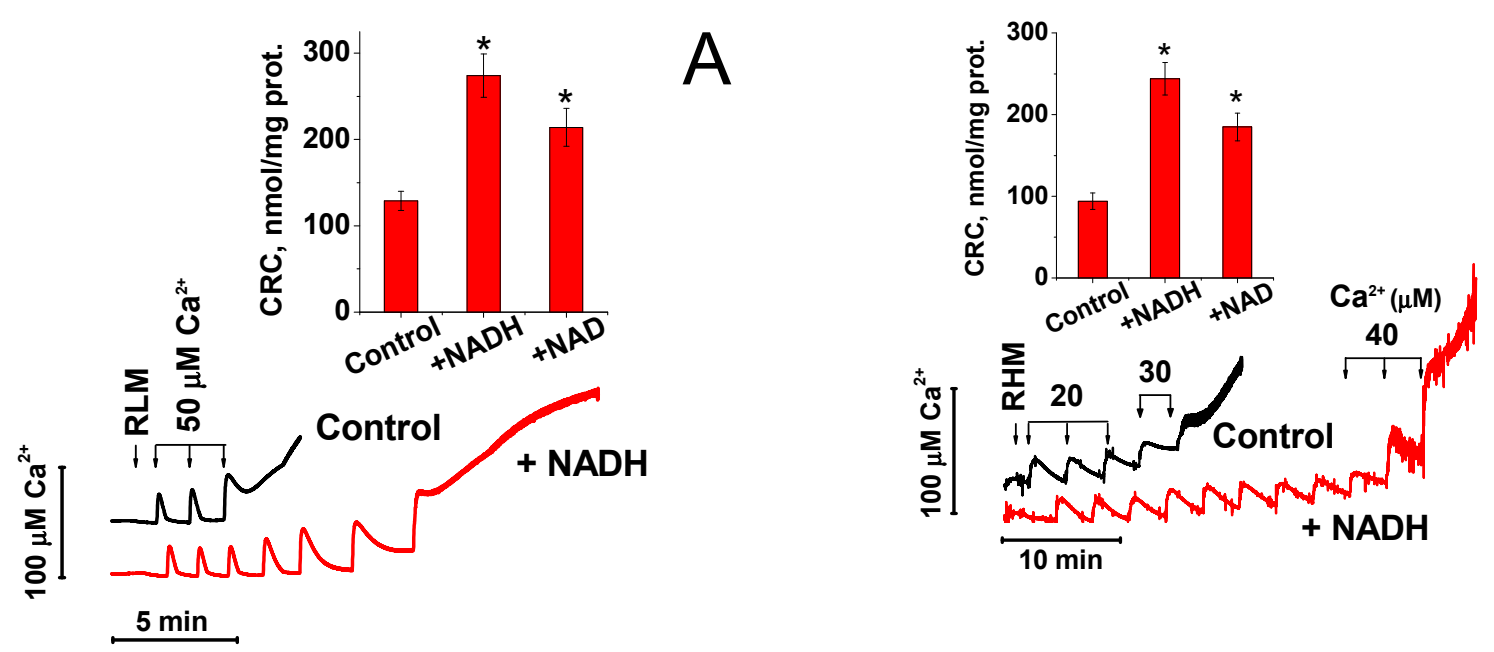

\section{B}

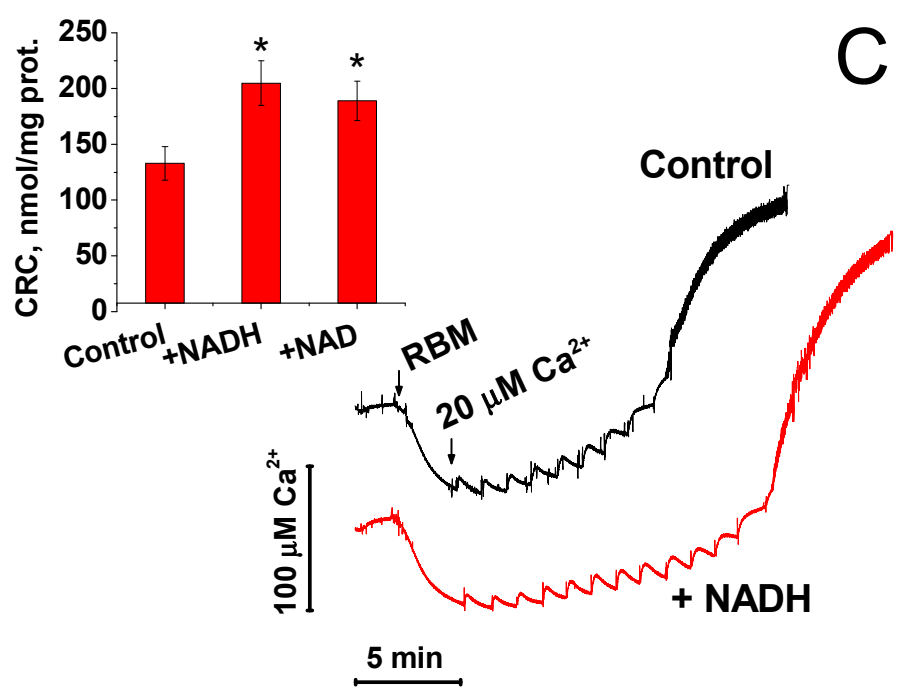

Figure 1. The effect of $\mathrm{NADH}$ and $\mathrm{NAD}^{+}$on the $\mathrm{CRC}$ of the liver (A), heart (B), and brain mitochondria (C). Prior to the measurements, mitochondria $(1 \mathrm{mg}$ prot. $/ \mathrm{mL})$ were added to the standard KCl-BM supplemented with $1 \mathrm{mM} \mathrm{NADH}$ or $1 \mathrm{mM} \mathrm{NAD}^{+}$. Arrows show the addition of $\mathrm{Ca}^{2+}$ by pulses of $20,30,40$, and $50 \mu \mathrm{M}$. Representative curves of $\mathrm{Ca}^{2+}$ accumulation are shown for RLM (A), RHM (B), and RBM (C). Bars in the inserts are the average values of retained $\mathrm{Ca}^{2+} \pm$ S.E.M $(n=6)$ for three or more independent experiments. ${ }^{*} p<0.01$.

2.2. Effect of $N A D(H)$ on the Concentration of $\mathrm{Ca}^{2+}$ in the Medium and the Rate of Its Uptake by Mitochondria

Adenine nucleotides are capable of chelating $\mathrm{Ca}^{2+}$ in solution. We examined whether the protective effect of NADH and $\mathrm{NAD}^{+}$is due to the binding of added $\mathrm{Ca}^{2+}$. Figure 2 shows that neither $2 \mathrm{mM}$ NADH (A) nor $2 \mathrm{mM} \mathrm{NAD}^{+}(\mathrm{B})$ caused a significant decrease in the concentration of $\mathrm{Ca}^{2+}$ in the incubation medium. Voltage-dependent anion-selective channels (VDAC) in the OMM and the mitochondria calcium uniporter in the IMM are the main gates for $\mathrm{Ca}^{2+}$-uptake by mitochondria [31]. $\mathrm{NAD}(\mathrm{H})$ is known to be capable of binding to VDAC and modulate its permeability to small molecules [29]. Therefore, we studied the effect of NADH and $\mathrm{NAD}^{+}$on the rate of $\mathrm{Ca}^{2+}$-uptake by mitochondria (Figure 2C,D). The figure demonstrates that neither NADH (C) nor $\mathrm{NAD}^{+}(\mathrm{D})$ inhibited the $\mathrm{Ca}^{2+}$ entry into mitochondria. Thus, it can be concluded that the protective effect of $\mathrm{NADH}$ and $\mathrm{NAD}^{+}$on the induction of $\mathrm{mPTP}$ by $\mathrm{Ca}^{2+}$ cannot be explained by the chelation of $\mathrm{Ca}^{2+}$ or the inhibition of its transport into mitochondria by the nucleotides. 

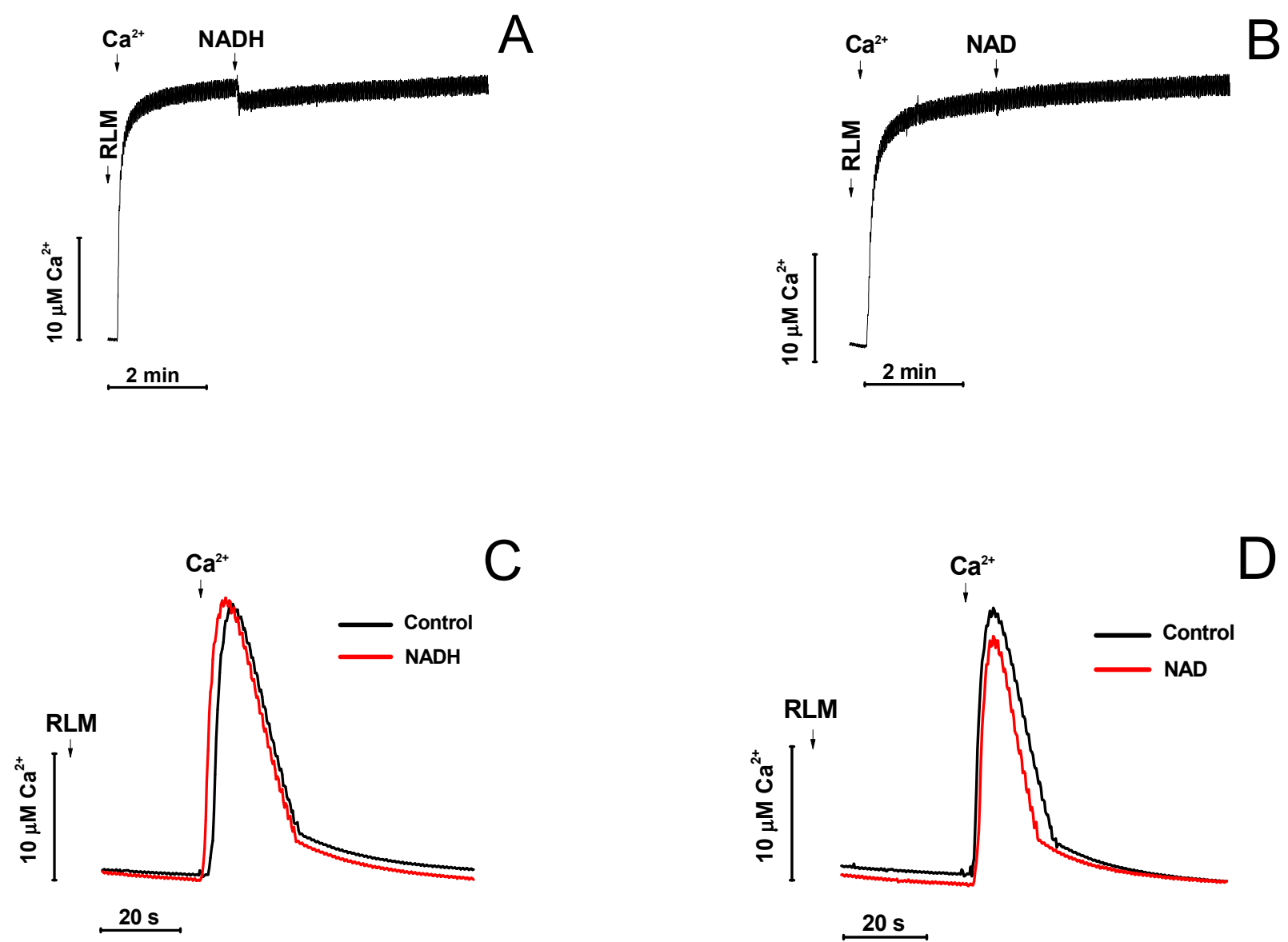

Figure 2. Effect of $\mathrm{NADH}$ and $\mathrm{NAD}^{+}$on the concentration of free $\mathrm{Ca}^{2+}$ in the incubation medium $(\mathbf{A}, \mathbf{B})$ and the rate of $\mathrm{Ca}^{2+}$ uptake by mitochondria $(\mathbf{C}, \mathbf{D})$. (A,B). KCl-BM without mitochondria was placed in a chamber equipped with a $\mathrm{Ca}^{2+}$-selective electrode. Arrows indicate the addition of $20 \mu \mathrm{M} \mathrm{Ca}^{2+}, 2 \mathrm{mM} \mathrm{NADH}(\mathbf{A})$, and $2 \mathrm{mM}$ NAD ${ }^{+}$(B). (C,D). RLM $(1 \mathrm{mg}$ prot. $/ \mathrm{mL})$ were placed in the KCl-BM supplemented, where indicated, with $1 \mathrm{mM} \mathrm{NADH}(\mathbf{C})$ or $1 \mathrm{mM} \mathrm{NAD}{ }^{+}(\mathbf{D})$. Two minutes later, $20 \mu \mathrm{M} \mathrm{Ca}^{2+}$ was added and its uptake was recorded. Representative curves of one experiment of at least three similar are shown.

\subsection{Divergent Effects of mPTP Closure on the Mitochondrial Shrinkage and $\Delta \Psi m$ Recovery in} $\mathrm{KCl}$ - and Sucrose-Based Media

It was previously shown that the opening of $\mathrm{MPTP}$ in mitochondria can be reversible $[9,32,33]$. We studied the effect of $\mathrm{mPTP}$ closure by a $\mathrm{Ca}^{2+}$ chelator (EGTA) and an mPTP inhibitor (CsA) on the shrinkage and repolarization of mitochondria in incubation media whose particles can (KCl-BM) or cannot (S-BM) be transported by mitochondrial carriers across the IMM (Figure 3). In $\mathrm{KCl}-\mathrm{BM}, \mathrm{Ca}^{2+}$-dependent mitochondrial swelling (A) and a decrease in $\Delta \Psi \mathrm{m}(\mathrm{C})$ was replaced by the shrinkage and restoration of $\Delta \Psi \mathrm{m}$ when EGTA and CsA were added to the mitochondrial suspension. In S-BM, the addition of EGTA and CsA did not result in mitochondrial contraction (B), although the mPTP was closed, as is evident by the complete recovery of $\Delta \Psi \mathrm{m}$ (D). Consequently, after the opening of mPTP and entry of sucrose molecules into the matrix, the swelling of mitochondria became irreversible even when the MPTP was closed. Taking this phenomenon into account, we developed an experimental model to find out the localization of the site of mPTP closure by added $\mathrm{NAD}(\mathrm{H})$. 

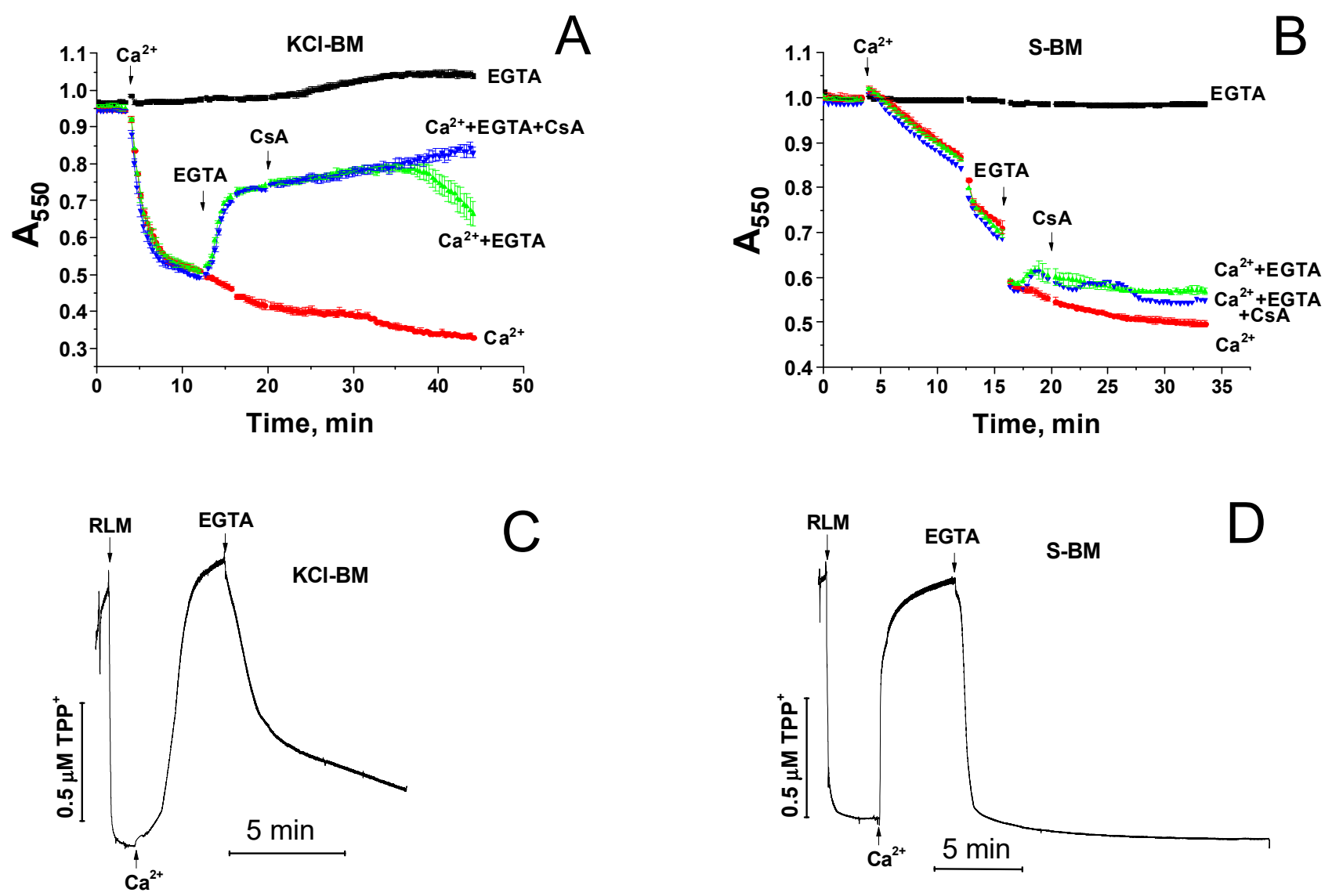

Figure 3. Effect of EGTA- and CsA-induced mPTP closure on the mitochondrial shrinkage $(\mathbf{A}, \mathbf{B})$ and $\Delta \Psi \mathrm{\Psi m}$ recovery $(\mathbf{C}, \mathbf{D})$ in KCl-BM and S-BM. A and B. Just before measurements, RLM (0.75 mg prot./mL) were added to KCl-BM (A) or S-BM (B) supplemented, where indicated, with $1 \mathrm{mM}$ EGTA. Arrows show the addition of $100 \mu \mathrm{M} \mathrm{Ca}^{2+}, 1 \mathrm{mM}$ EGTA, and $1 \mu \mathrm{M}$ CsA. (C,D). Prior to the measurements, $1.5 \mu \mathrm{M}$ TPP ${ }^{+}$was added to KCl-BM (C) or S-BM (D). Arrows show the addition of RLM $(1 \mathrm{mg}$ prot. $/ \mathrm{mL}), 100(\mathrm{C})$ and $400 \mu \mathrm{M} \mathrm{Ca}^{2+}(\mathrm{D})$, and $1 \mathrm{mM}$ EGTA. Representative curves of one experiment of at least three similar are shown.

\subsection{Effect of $\mathrm{NAD}(\mathrm{H})$ on the $\mathrm{Ca}^{2+}$-Induced Mitochondrial Swelling in $\mathrm{KCl}$-and Sucrose-Based Media}

Based on the data presented in Figure 3, one can conclude that, if $\mathrm{NAD}(\mathrm{H})$ closes the mPTP by acting on the regulatory site in the matrix after passing through the pore, then in $\mathrm{S}-\mathrm{BM}$, in contrast to $\mathrm{KCl}-\mathrm{BM}$, the protective effect will disappear. Therefore, we examined the effect of added NADH and $\mathrm{NAD}^{+}$on the rate of $\mathrm{Ca}^{2+}$-induced mitochondrial swelling in KCl-BM and S-BM (Figure 4). As it follows from Figure 3, in both KCl-BM (A) and S-BM (B), NADH and $\mathrm{NAD}^{+}$effectively inhibited the mitochondrial swelling. Furthermore, the addition of $\mathrm{NADH}\left(\mathrm{C}\right.$ and $\mathrm{D}$ ) and $\mathrm{NAD}^{+}$(not shown) after the mPTP opening did not result in mitochondrial repolarization, whereas EGTA restored $\triangle \Psi \mathrm{m}$. These data directly indicate that $\mathrm{NAD}(\mathrm{H})$ added from the cytosolic side inhibits the opening rather than activating the closing of mPTP. 

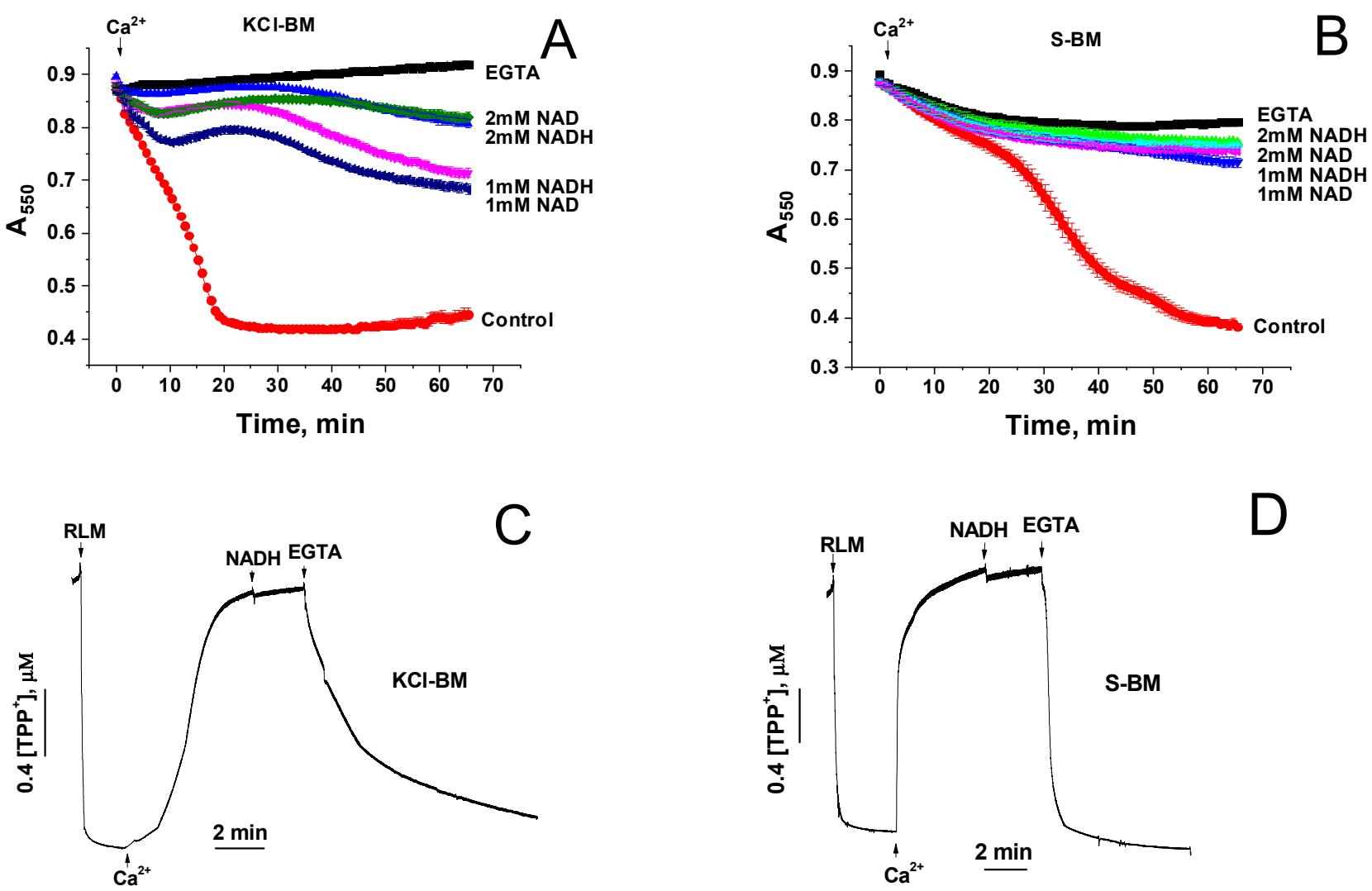

Figure 4. Effect of $\mathrm{NADH}$ and $\mathrm{NAD}^{+}$on the $\mathrm{Ca}^{2+}$-induced mitochondrial swelling in $\mathrm{KCl}-\mathrm{BM}(\mathrm{A})$ and S-BM (B). Prior to the measurements, RLM $(0.75 \mathrm{mg}$ prot. $/ \mathrm{mL})$ were added to $\mathrm{KCl}-\mathrm{BM}$ or S-BM supplemented, where indicated, with $1 \mathrm{mM}$ EGTA and 1-2 mM NADH and NAD ${ }^{+}$. Arrows show the addition of $100 \mu \mathrm{M} \mathrm{Ca}^{2+}$. (C,D). Effect of NADH and EGTA on the recovery of $\triangle \Psi \mathrm{m}$ in $\mathrm{KCl}-\mathrm{BM}$ and S-BM. Just before measurements, $1.5 \mu \mathrm{M} \mathrm{TPP}^{+}$was added to $\mathrm{KCl}-\mathrm{BM}(\mathrm{C})$ or S-BM (D). Arrows show the addition of RLM (1 mg prot. $/ \mathrm{mL}), 100$ (C) and $400 \mu \mathrm{M} \mathrm{Ca}^{2+}$ (D), $1 \mathrm{mM}$ NADH, and $1 \mathrm{mM}$ EGTA. Representative curves of one experiment of at least three similar are shown.

\subsection{Effect of $N A D(H)$ on the $C a^{2+}$-Induced Loss of $\triangle \Psi m$ and Calcein Release from Individual Mitochondria}

There is a probability that external $\mathrm{NAD}(\mathrm{H})$ affecting the internal regulatory site through the opened mPTP causes its fast closure even before large changes in the mitochondrial volume. Since mPTP closure is not always accompanied by mitochondrial repolarization [29], one may suggest that $\mathrm{NAD}(\mathrm{H})$ induces $\mathrm{mPTP}$ closure without the restoration of $\triangle \Psi \mathrm{m}$, in contrast to the EGTA-induced one. To clarify this issue, we studied the effect of NADH and $\mathrm{NAD}^{+}$on the dynamics of the $\mathrm{Ca}^{2+}$-dependent decrease in $\Delta \Psi \mathrm{m}$ (TMRM) and the release of the fluorescent dye calcein from individual mitochondria of hepatocytes permeabilized with digitonin (Figure 5). Since the sizes of calcein and NAD $(H)$ molecules are similar (620 and $663 \mathrm{Da}$, respectively), the beginning of the release of calcein from mitochondria corresponds to the moment when the membrane becomes permeable to $\mathrm{NADH}$. 

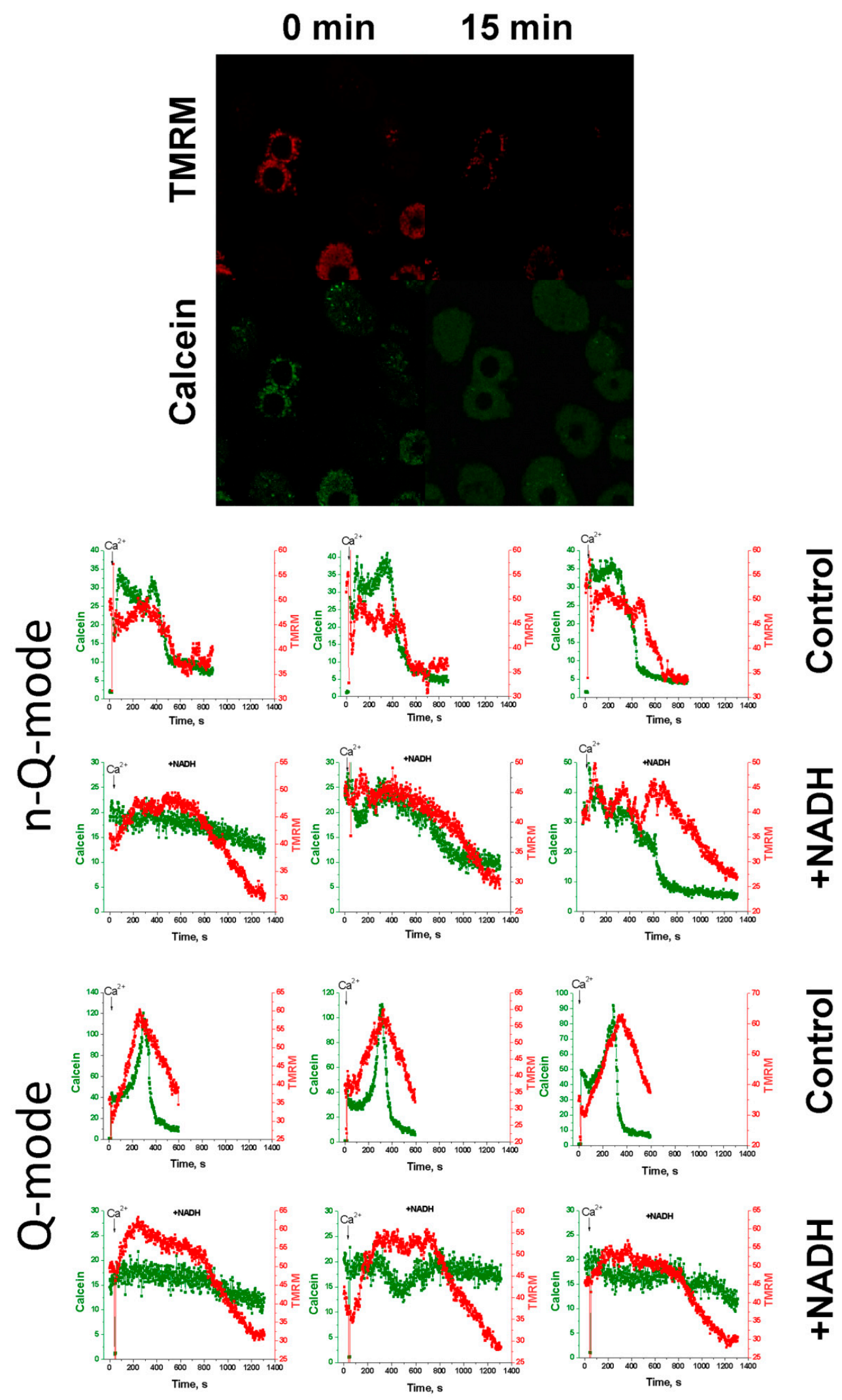

Figure 5. Effect of $\mathrm{NADH}$ on the $\mathrm{Ca}^{2+}$-induced loss of $\triangle \Psi \mathrm{m}$ and calcein release from individual mitochondria. Isolated rat hepatocytes were stained with $5 \mu \mathrm{M}$ calcein-AM and 100 (n-Q-mode) and $300 \mathrm{nM}$ (Q-mode) TMRM. The cell incubation medium was replaced by mitochondria-supporting medium (125 mM KCl, $20 \mathrm{mM}$ sucrose, $10 \mathrm{mM} \mathrm{HEPES} \mathrm{(pH} \mathrm{7.3),} 5$ mM succinate, $2.5 \mu \mathrm{g} / \mathrm{mL}$ rotenone, and $40 \mu \mathrm{M}$ digitonin) supplemented, where indicated, with 2 mM NADH two minutes before the addition of $50 \mu \mathrm{M} \mathrm{Ca}^{2+}$. Representative traces of the dynamics of TMRM (red) and calcein fluorescence (green) in 12 selected mitochondria of 180 total from three separate experiments are shown. 
TMRM, at high concentrations, is known to quench the own fluorescence and the fluorescence of calcein (quenching mode, Q-mode) [34,35]. To prevent quenching, the concentration of TMRM in many studies was low $(<40 \mathrm{nM}$ ) (non-quenching mode, n-Qmode) $[36,37]$. However, during prolonged incubation, calcein may leak from mitochondria or undergo photobleaching, which interferes with the detection of the moment of mPTP opening. Therefore, a Q-mode sharp increase in the calcein fluorescence just before the opening of the pore [34,35] can be a convenient indicator of the initiation of the process (third line of panels). Figure 5 shows that, in the n-Q-mode (first and second lines of panels), NADH postponed the $\mathrm{Ca}^{2+}$-dependent high-amplitude drop in the TMRM and calcein fluorescence; in the Q-mode (third and fourth lines of panels), NADH delayed and decreased the amplitude of both the rise and decline in the TMRM and calcein fluorescence. Hence, NADH preserved $\triangle \Psi \mathrm{m}$ and precluded the PTP opening in mitochondria of permeabilized hepatocytes. These data convincingly indicate that $\mathrm{NAD}(\mathrm{H})$ suppresses the PTP opening, acting through the external site in the OMM or the outer surface of the IMM.

\subsection{Protective Effect of $\mathrm{NAD}(\mathrm{H})$ Is Due to the Suppression of $\mathrm{Ca}^{2+}$-Dependent Permeabilization of the Inner Mitochondrial Membrane}

One can propose two main mechanisms by which the external $\mathrm{NAD}(\mathrm{H})$ is capable of suppressing the $\mathrm{Ca}^{2+}$-dependent mitochondrial swelling: (1) a direct suppression of the $\mathrm{mPTP}$ opening through an external regulatory site and (2) suppression of the entrance of solutes into the intermembrane space and matrix by the VDAC blockage. In the second case, $\mathrm{NAD}(\mathrm{H})$ must not inhibit the $\mathrm{Ca}^{2+}$-dependent dissipation of $\triangle \Psi \mathrm{m}$ because the proton gradient is created across the IMM, whereas $\mathrm{NAD}(\mathrm{H})$ does not affect the rate of $\mathrm{Ca}^{2+}$ accumulation by mitochondria (see Figure 2). Figure 6 demonstrates that, in mitochondrial suspension, $1 \mathrm{mM}$ NADH considerably delayed the $\mathrm{Ca}^{2+}$-dependent dissipation of $\Delta \Psi \mathrm{m}$ measured by the membrane-penetrating lipophilic cations TMRM (A) and $\mathrm{TPP}^{+}(\mathrm{B})$. The addition of the uncoupler FCCP at the end of the measurements shows that NADH does not restrict the free passage of lipophilic dyes through the membranes. Hence, the data obtained indicate the existence of an external site of regulation of the MPTP state.
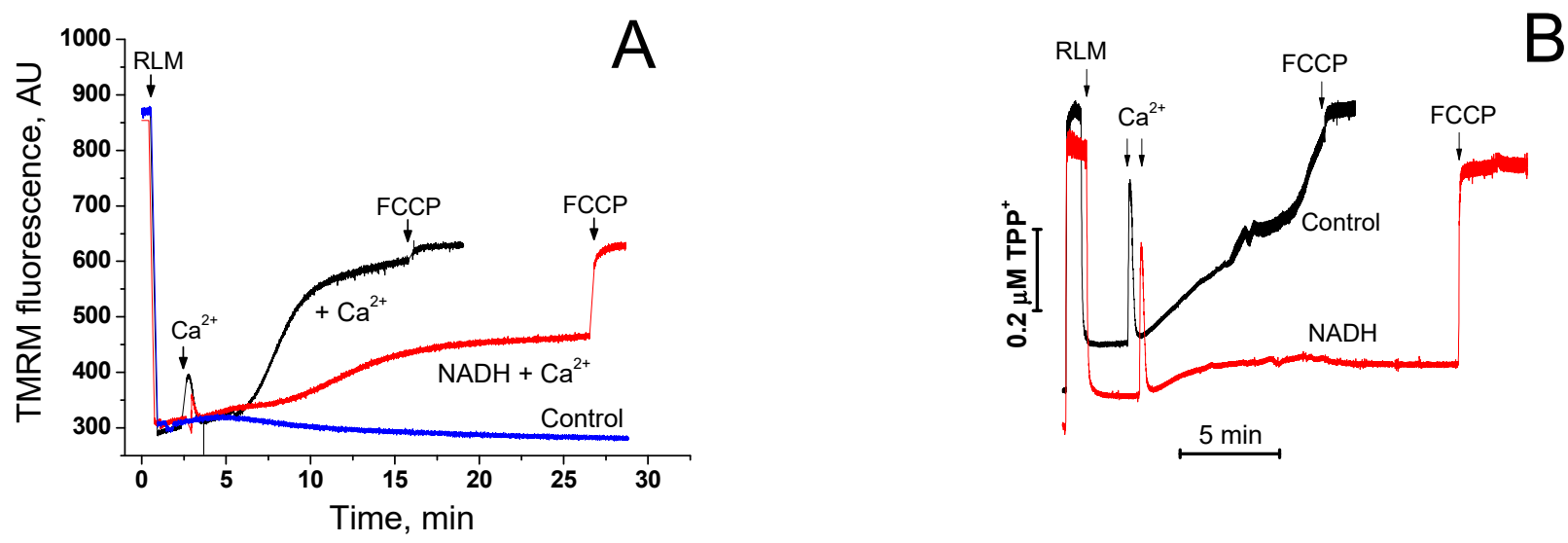

Figure 6. Effect of NADH on the $\mathrm{Ca}^{2+}$-dependent dissipation of $\triangle \Psi \mathrm{m}$ in mitochondrial suspension. Prior to the measurements, $150 \mathrm{nM}$ TMRM (A) or $1 \mu \mathrm{M} \mathrm{TPP}{ }^{+}(\mathbf{B})$ were added to KCl-BM. Arrows show the addition of RLM (0.3 (A) and $1 \mathrm{mg}$ prot./mL (B), $50(\mathbf{A})$ and $200 \mu \mathrm{M} \mathrm{Ca}^{2+}(\mathbf{B})$, and $500 \mathrm{nM} \mathrm{FCCP.} \mathrm{Each} \mathrm{panel} \mathrm{provides} \mathrm{representative} \mathrm{curves} \mathrm{of} \mathrm{one} \mathrm{experiment}$ of three similar.

\section{Discussion}

It is well documented that pyridine nucleotides of the mitochondrial matrix are involved in the regulation of mPTP. NADH and $\mathrm{NAD}^{+}$suppress the opening of $\mathrm{mPTP}$ by acting on the internal allosteric regulatory site $[8,9]$ and increasing the CRC of mitochondria $[10,11]$. NADPH participates in the enzymatic reduction of glutathione, which, in turn, supports critical thiols of $\mathrm{mPTP}$ in a reduced state and thus suppresses the MPTP 
opening $[10,11,38,39]$. Mitochondrial transhydrogenase integrates the protective effects of $\mathrm{NADH}$ and $\mathrm{NADPH}$, mediating the $\triangle \Psi \mathrm{m}$ - and $\mathrm{NADH}$-dependent reduction of $\mathrm{NADP}+$ to NADPH [40].

Recently, we have shown for the first time that "external" or "cytosolic" NAD $(H)$ can effectively suppress the opening of $\mathrm{MPTP}$ in mitochondria of terminally differentiated cells [23]. However, the experimental models used in the study left some possibility that external $\mathrm{NAD}(\mathrm{H})$ closed $\mathrm{mPTP}$ by acting on the internal regulatory site after the entry into the matrix through the open pore. In the present work, we provide unequivocal evidence for the existence of a $\mathrm{NAD}(\mathrm{H})$-dependent "external" site of mPTP regulation located in the OMM, IMS, or at the outer surface of the IMM. The evidence is based on three effects of added $\mathrm{NAD}(\mathrm{H})$ on mitochondria: (1) on the increase in the CRC of isolated mitochondria (see Figure 1); (2) on mitochondrial swelling in sucrose- and KCl-containing media (see Figure 4); and (3) on the release of entrapped calcein from the mitochondria of permeabilized cells (see Figure 5).

The opening of mPTP is associated with a decrease in the $\Delta \Psi \mathrm{m}$, the release of accumulated $\mathrm{Ca}^{2+}$ and $\mathrm{Mg}^{2+}$ from mitochondria, and entry into the matrix of solutes with an average particle size of up to $1.5 \mathrm{kDa}$ and even larger. The dissipation of $\Delta \Psi \mathrm{m}$, swelling in $\mathrm{KCl}-\mathrm{BM}, \mathrm{Ca}^{2+} / \mathrm{Mg}^{2+}$ release, and swelling in S-BM require pores with minimum radii of $0.14,0.35,0.42$, and $0.52 \mathrm{~nm}$, respectively, which correspond to the hydrodynamic radii of solvated particles [32,41,42]. However, the dissipation of $\Delta \Psi \mathrm{m}$ and the release of $\mathrm{Ca}^{2+}$ and $\mathrm{Mg}^{2+}$ can be separated in time from the initiation of the sucrose and mannitol entry into the matrix by classical mPTP inhibitors (EGTA, CsA, ADP, $\mathrm{Mg}^{2+}$, and BSA) $[29,43]$. Moreover, the release of $\mathrm{Ca}^{2+}$ from mitochondria can occur upon the $\Delta \Psi \mathrm{m}$ loss and oxidation of endogenous pyridine nucleotides without the MPTP opening [44-46]. Therefore, it is logical to assume that relatively large molecules such as $\mathrm{NAD}(\mathrm{H})(0.6 \mathrm{~nm})$ will not be able to enter the mitochondrial matrix through the opened $\mathrm{mPTP}$ before a significant portion of the accumulated $\mathrm{Ca}^{2+}$ is released from mitochondria. It is reasonable that this should affect the kinetics of $\mathrm{Ca}^{2+}$ accumulation by mitochondria. Since we observed a NAD(H)-dependent increase in the number of loaded pulses of $\mathrm{Ca}^{2+}$ without any noticeable changes in the kinetics of the uptake (see Figure 1), this is a strong argument in favor of the existence of an external regulatory site.

Recording the $\mathrm{Ca}^{2+}$-dependent release of the $\Delta \Psi \mathrm{m}$-sensitive probe TMRM and the membrane-impermeable form of calcein from mitochondria by a confocal microscope makes it possible to directly determine the point in time when the internal regulatory site becomes accessible to the external $\mathrm{NAD}(\mathrm{H})$ (see Figure 5). In our experiments, we applied TMRM at two concentrations, which can (Q-mode) and cannot (n-Q-mode) quench the fluorescence of TMRM and calcein. It should be noted that usually lower TMRM concentrations are used in the studies of the PTP in cells [36,37]. However, the application of TMRM at higher concentrations has some advantages. Indeed, the quenching of TMRM and calcein fluorescence by high TMRM concentrations in the mitochondrial matrix terminates with the beginning of TMRM release, which facilitates the detection of the start of the mPTP opening [34,35]. According to our data, NADH considerably increased the time between the addition of $\mathrm{Ca}^{2+}$ and the release of calcein from mitochondria of hepatocytes and decreased the amplitude of fluctuations in $\triangle \Psi \mathrm{m}$. These data demonstrate that NADH entrance into the matrix is unnecessary for the MPTP inhibition.

The strongest evidence for the mPTP regulation through an external NAD $(\mathrm{H})$-binding site came from the data presented in Figures 3 and 4. It is well known that the IMM contains specialized transport systems for the uptake and extrusion of $\mathrm{K}^{+}$and $\mathrm{Cl}^{-}$ions, but not for sucrose and $\operatorname{NAD}(\mathrm{H})$ [47-50]. Therefore, with the opening of mPTP (non-selective channel) in $\mathrm{KCl}-\mathrm{BM}$ and S-BM, both ions and sucrose enter into the matrix, causing the mitochondrial swelling. The closure of $\mathrm{MPTP}$ in $\mathrm{KCl}-\mathrm{BM}$ causes the IMM repolarization, pumping out of ions from the matrix, and the restoration of the mitochondrial volume. In S-BM, due to the absence of sucrose transport systems, the IMM repolarization occurs without the restoration of the mitochondrial volume (see Figure 3). Considering the size of 
sucrose and NAD $(H)$ particles and their ratio in the incubation medium (500-125:1), one can assume that the accumulation of $\mathrm{NAD}(\mathrm{H})$ in the matrix sufficient for mPTP closure through the internal site must be accompanied by the accumulation of sucrose sufficient for high-amplitude swelling. Therefore, the effect of suppression of the mitochondrial swelling by the added $\mathrm{NAD}(\mathrm{H})$ should disappear in S-BM. The fact that $\mathrm{NAD}(\mathrm{H})$ demonstrates a potent protective effect in both $\mathrm{KCl}$ - and S-BM but fails to induce rapid repolarization of the IMM (see Figure 4) is direct evidence for the existence of an external NAD(H)-binding site for the MPTP regulation.

Presumably, the mechanism of mPTP suppression by external NAD $(\mathrm{H})$ is distinct from the chelating of free $\mathrm{Ca}^{2+}$ by the nucleotide (see Figure 2). It was previously shown that the binding of $\mathrm{NAD}(\mathrm{H})$ to VDAC can restrict the movement of large (ATP/ADP) anions through the channel [50-52]. Other VDAC blockers inhibited the transport of small (superoxide) anions through the channel $[53,54]$. In addition, some data indicate that NADH and $\mathrm{NAD}^{+}$can limit the permeability of the VDAC to $\mathrm{Ca}^{2+}$ and other small ions [32]. However, our experiments did not reveal any noticeable effect of $\mathrm{NAD}(\mathrm{H})$ on the rate of $\mathrm{Ca}^{2+}$ accumulation by mitochondria (see Figure 2), although the effect on the rate of MPTP induction (see Figure 4) and the CRC value (see Figure 1) was significant. Besides, the protective effect of $\mathrm{NAD}(\mathrm{H})$ does not appear to be associated with the restriction of the movement of incubation medium particles across the OMM, since the nucleotide suppressed both mitochondrial swelling and $\Delta \Psi \mathrm{m}$ dissipation across the IMM (see Figure 6). Thus, the mechanism of NAD(H)-dependent inhibition of mPTP opening is most likely associated with pore stabilization in the closed state.

Despite the relatively low number of "external" NAD(H)-binding proteins that fit for the role of the $\mathrm{mPTP}$ regulator [23], some properties of the regulator extremely complicate its identification. Indeed, rather high effective concentrations of NADH and $\mathrm{NAD}^{+}$for the inhibition of mPTP opening (IC50 $\geq 200$ and $700 \mu \mathrm{M}$, respectively) indicate a low affinity of the regulator for the nucleotides. Besides, it is currently unknown whether the nicotinamide or adenine moiety of the $\mathrm{NAD}(\mathrm{H})$ molecule makes the major contribution to the $\mathrm{mPTP}$ suppression. In addition, integral membrane proteins require association with lipids to maintain their native structure and, hence, native structure for NAD $(H)$ binding. All these peculiarities make the identification of the regulator by the immunoprecipitation method quite problematic. Earlier, we have supposed that the external mPTP regulator is one of the VDAC isoforms [30]. Indeed, VDAC can bind NADH and $\mathrm{NAD}^{+}$with $\mathrm{Kd}$ of 87 and $680 \mu \mathrm{M}$, respectively [52,55]. Besides, VDAC is involved in the mPTP regulation [56] and interacts with other mPTP-regulating proteins: ANT, HKs I/II, and GAPDH [57-61]. However, regardless of the level of VDAC isoforms, the protective effect of NAD $(H)$ in mitochondria of all cancer and undifferentiated cell lines we tested was absent or weak. This did not allow us to verify the hypothesis using the genetic knockout of candidate proteins. Thus, the molecular nature of the external NAD $(\mathrm{H})$-dependent $\mathrm{mPTP}$ regulator calls for further clarification.

To conclude, here we presented unequivocal evidence for the existence of an external mitochondrial NAD(H)-dependent site for the mPTP regulation. This finding is of considerable importance for the understanding of the mechanisms of mPTP control in vivo. Indeed, the existence of the site can explain the reasons for the additive inhibitory effects of cytosolic adenine and pyridine nucleotides on MPTP [23] and the resistance of mitochondria of excitable cells (cardiocytes, neurons) to long-term cyclic $\mathrm{Ca}^{2+}$ loads. In addition, the identification of the $\mathrm{NAD}(\mathrm{H})$-binding regulator may allow the development of its high-affinity ligands for pharmacological stimulation or suppression of mPTP in various pathologies. Therefore, we believe that the results presented in this work will attract the attention of researchers and stimulate the development of this promising line of research. 


\section{Materials and Methods}

\subsection{Materials}

Bovine serum albumin (BSA) (A2153), carbonyl cyanide p-(trifluoromethoxy)phenylhydrazone (FCCP) (C2920), CsA (30024), digitonin (D141), 4-(2-hydroxyethyl)piperazine1-ethanesulfonic acid (HEPES) (H3375), NADH (N8129), NAD ${ }^{+}$(N6522), rhodamine 123 (R8004), rotenone (R8875), sucrose (S7903), succinate (S3674), SF-6847 / Tyrphostin A9 (T182), $\mathrm{TPP}^{+}$(218790), Trizma Base (93352), were purchased from the Sigma-Aldrich Corporation (St. Louis, MO, USA). Ethylene glycol-bis(2-aminoethylether)- $\mathrm{N}, \mathrm{N}, \mathrm{N}^{\prime}, \mathrm{N}^{\prime}$-tetraacetic acid (EGTA) (A0878,0025) was from PanReac ApppliChem. Tetramethylrhodamine, methyl ester (TMRM), and Calcein-AM were from Thermofisher (Waltham, Massachusetts, USA). Cell-Tak (354240) (Corning, New York, NY, USA) was kindly provided by Dr. Polina Kotova from the ICB RAS. Other chemicals were of analytical grade and were purchased from local suppliers.

\subsection{Isolation of Mitochondria from Rat Liver, Heart, and Brain}

All manipulations with animals, before the isolation of the organs, were performed in accordance with the Helsinki Declaration of 1975 (revised in 1983), national requirements for the care and use of laboratory animals, and protocol 9/2020 of 17.02.2020 approved by the Commission on Biological Safety and Bioethics at the ITEB RAS. Adult male Wistar rats were decapitated after anesthesia with $\mathrm{CO}_{2}$. Rat liver mitochondria (RLM) were isolated by a standard differential centrifugation procedure [62]. The homogenization medium contained $220 \mathrm{mM}$ mannitol, $70 \mathrm{mM}$ sucrose, $10 \mathrm{mM}$ HEPES (pH adjusted to 7.4 with Trizma Base), $1 \mathrm{mM}$ EGTA, and 0.05\% BSA. The mitochondrial pellet was washed three times with a medium devoid of EGTA and BSA. Final pellets were resuspended in this medium to yield $\sim 70 \mathrm{mg}$ protein $/ \mathrm{mL}$.

Rat heart mitochondria (RHM) were isolated in the same buffer in a similar way except the mitochondrial pellet was washed twice. The concentration of isolated RHM was approximately $20 \mathrm{mg}$ protein $/ \mathrm{mL}$.

Rat brain mitochondria (RBM) were isolated as described in [63] with minor modifications. The homogenization medium contained $320 \mathrm{mM}$ sucrose, $10 \mathrm{mM}$ Tris (pH adjusted to 7.4 with Trizma Base), $0.5 \mathrm{mM}$ EGTA and $0.5 \mathrm{mM}$ EDTA. The brain was homogenized in a Potter homogenizer ( $800 \mathrm{rpm}, 20$ passages). The homogenate was centrifuged twice for $4 \mathrm{~min}$ at $2000 \times \mathrm{g}$ and each time the precipitate was discarded. A "crude" mitochondrial pellet containing synaptosomes, myelin, and non-synaptic RBM was obtained by sedimentation from supernatant at $12,500 \times g$ for $11 \mathrm{~min}$. Then, RBM was purified by the sedimentation $(17,500 \times g$ for $11 \mathrm{~min})$ in a discontinuous Percoll gradient $(3,10,15$, and $24 \%$ Percoll in the isolation medium). The fraction of nonsynaptic mitochondria was collected and washed once in an isolation medium free of EGTA $(11,500 \times g, 11 \mathrm{~min})$. The concentration of isolated RBM was approximately $20 \mathrm{mg}$ protein $/ \mathrm{mL}$.

Measurements were performed at $37^{\circ} \mathrm{C}$ either in a $\mathrm{KCl}$-based medium (KCl-BM) or in a sucrose-based medium (S-BM). $\mathrm{KCl}$-BM contained $125 \mathrm{mM} \mathrm{KCl}, 20 \mathrm{mM}$ sucrose, $10 \mathrm{mM}$ HEPES (pH adjusted to 7.3 with Trizma Base), $2 \mathrm{mM} \mathrm{KH}_{2} \mathrm{PO}_{4}, 2 \mathrm{mM} \mathrm{MgCl}_{2}, 5 \mathrm{mM}$ succinate, and $2.5 \mu \mathrm{M}$ rotenone. S-BM was composed of $280 \mathrm{mM}$ sucrose, $10 \mathrm{mM}$ HEPES (pH 7.3), $2 \mathrm{mM} \mathrm{KH}{ }_{2} \mathrm{PO}_{4}, 2 \mathrm{mM} \mathrm{MgCl} 2,5 \mathrm{mM}$ succinate, and $2.5 \mu \mathrm{M}$ rotenone. Other experimental details are given in the figures and figure legends. Mitochondrial protein was assayed by the Biuret method using BSA as a standard [64].

\subsection{Isolation of Rat Hepatocytes}

Hepatocytes were isolated from 1 day-fasted rats (200-300 g) by collagenase digestion [65]. Livers were perfused with $0.3 \mathrm{mg} / \mathrm{mL}$ collagenase (Type IV) through the portal vein. Hepatocytes were separated from nonparenchymal cells by centrifugation at $50 \times g$ for $2 \mathrm{~min}$ at $4{ }^{\circ} \mathrm{C}$. The viability of isolated hepatocytes was assessed by the trypan blue exclusion test and usually exceeded $80 \%$. Isolated hepatocytes were stored in ice in Krebs- 
Ringer-HEPES buffer ( $130 \mathrm{mM} \mathrm{NaCl}, 3 \mathrm{mM} \mathrm{KCl}, 2 \mathrm{mM} \mathrm{CaCl}_{2}, 1 \mathrm{mM} \mathrm{KH}_{2} \mathrm{PO}_{4}, 1 \mathrm{mM}$ $\mathrm{MgSO}_{4}$, and $20 \mathrm{mM}$ HEPES (pH 7.35) supplemented with $0.2 \%$ BSA.

\subsection{Determination of the $\mathrm{Ca}^{2+}$ Uptake Rate and the $\mathrm{Ca}^{2+}$-Retention Capacity of Mitochondria}

Mitochondrial $\mathrm{Ca}^{2+}$ uptake and release were recorded in a temperature-controlled electrode chamber using a $\mathrm{Ca}^{2+}$-selective electrode (Niko Analyt, Moscow, Russia) connected to a computerized recording system Record 4 (ITEB RAS). The electrode was calibrated with known amounts of $\mathrm{Ca}^{2+}$ at the beginning of each experimental series. The CRC was defined as the amount of $\mathrm{Ca}^{2+}$ taken up by mitochondria in small pulses before the $\mathrm{Ca}^{2+}$ release. Other experimental details are given in the figure legends.

\subsection{Recording of Mitochondrial Swelling}

The opening of MPTP in isolated mitochondria was registered as the initiation of EGTA- and CsA-sensitive high-amplitude swelling. Mitochondrial swelling was determined by measuring a decrease in $\mathrm{A}_{550}$ in mitochondrial suspension using a plate reader (Infinite 200 Tecan, Groedig, Austria) and 96-well plates. Other details are given in the figures and figure legends.

\subsection{Recording of the Mitochondrial Membrane Potential}

$\Delta \Psi \mathrm{m}$ across the IMM was measured using either an Infinite 200 plate reader or a $\mathrm{TPP}^{+}$-selective electrode (Niko Analyt, Moscow, Russia) connected to the recording system Record 4. For fluorescent and potentiometric measurements, incubation media contained either $330 \mathrm{nM}$ rhodamine 123 (Ex $480 \mathrm{~nm}$, Em $525 \mathrm{~nm}$ ) or $1.5 \mu \mathrm{M} \mathrm{TPP}^{+}$.

\subsection{Registration of mPTP Opening by Confocal Microscopy}

Hepatocytes were stained with $5 \mu \mathrm{M}$ calcein-AM and 100 (non-quenching mode) or $300 \mathrm{nM}$ (quenching mode) $\Delta \Psi \mathrm{m}$-sensitive dye TMRM at $37^{\circ} \mathrm{C}$ for $15 \mathrm{~min}$. Then, hepatocytes were set on a glue (Cell-Tak), and the Krebs-Ringer-Hepes buffer was gently washed out and replaced by KCl-BM supplemented with digitonin $\left(40 \mu \mathrm{M} /\left(\mathrm{mL} \cdot 10^{6}\right.\right.$ cells) $)$, and, where specified, $\mathrm{NADH}$ and $\mathrm{NAD}^{+}$at indicated concentrations. The dissipation of $\triangle \Psi \mathrm{m}$ and the opening of mPTP in selected mitochondria were recorded at 540/517-600 and 488/520-570 nm Ex/Em, respectively, as described by Hüser et al. [34,35].

\subsection{Statistical Analysis}

All original curves are representative of one experiment of at least three similar. The values on all swelling/shrinkage and $\Delta \Psi \mathrm{m}$ curves measured by rhodamine 123 are the means \pm standard error of the mean (S.E.M.) for three wells $(n=3)$. Bars are the means \pm S.E.M. from three or more experiments. Statistical significance $(p)$ was determined using the Student's $t$-test.

Author Contributions: Investigation, E.K., A.N. and A.K.; writing-original draft preparation, E.K., A.N. and A.K.; writing—review and editing, A.K.; visualization, E.K. and A.N.; supervision and project administration, A.K. All authors have read and agreed to the published version of the manuscript.

Funding: This work was supported by a State assignment to the Institute of Theoretical and Experimental Biophysics, Russian Academy of Sciences (ITEB RAS) 075-00381-21-00.

Institutional Review Board Statement: All manipulations with animals before the isolation of organs were performed in accordance with the Helsinki Declaration of 1975 (revised in 1983), national requirements for the care and use of laboratory animals, and protocol 9/2020 of 17.02.2020 approved by the Commission on Biological Safety and Bioethics at the ITEB RAS.

Informed Consent Statement: Not applicable.

Data Availability Statement: Data is contained within the article. 
Acknowledgments: A part of experiments was conducted using the equipment of Optical Microscopy and Spectrophotometry core facility, Institute of Cell Biophysics (ICB RAS), Federal Research Center "Pushchino Scientific Center for Biological Research of the Russian Academy of Sciences".

Conflicts of Interest: The authors declare no conflict of interest.

\section{References}

1. Chaudhuri, R.C.; Nussenzweig, A. The multifaceted roles of PARP1 in DNA repair and chromatin remodeling. Nat. Rev. Mol. Cell Biol. 2017, 18, 610-621. [CrossRef] [PubMed]

2. Imai, S.; Guarente, L. NAD+ and sirtuins in aging and disease. Trends Cell Biol. 2014, 24, 464-471. [CrossRef] [PubMed]

3. Hernández-Jiménez, M.; Hurtado, O.; Cuartero, M.I.; Ballesteros, I.; Moraga, A.; Pradillo, J.M.; McBurney, M.W.; Lizasoain, I.; Moro, M.A. Silent information regulator 1 protects the brain against cerebral ischemic damage. Stroke 2013, 44, $2333-2337$. [CrossRef] [PubMed]

4. Hafner, A.V.; Dai, J.; Gomes, A.P.; Xiao, C.Y.; Palmeira, C.M.; Rosenzweig, A.; Sinclair, D.A. Regulation of the mPTP by SIRT3mediated deacetylation of CypD at lysine 166 suppresses age-related cardiac hypertrophy. Aging 2010, 2, 914-923. [CrossRef] [PubMed]

5. Chini, E.N. CD38 as a regulator of cellular NAD: A novel potential pharmacological target for metabolic conditions. Curr. Pharmm. Des. 2009, 15, 57-63. [CrossRef]

6. Aksoy, P.; White, T.A.; Thompson, M.; Chini, E.N. Regulation of intracellular levels of NAD: A novel role for CD38. Biochem. Biophys. Res. Commun. 2006, 345, 1386-1392. [CrossRef]

7. Rasola, A.; Bernardi, P. The mitochondrial permeability transition pore and its involvement in cell death and in disease pathogenesis. Apoptosis 2007, 12, 815-833. [CrossRef] [PubMed]

8. Hunter, D.R.; Haworth, R.A. The Ca2+-induced membrane transition in mitochondria. I. The protective mechanisms. Arch Biochem. Biophys. 1979, 195, 453-459. [CrossRef]

9. Haworth, R.A.; Hunter, D.R. Allosteric inhibition of the Ca2+-activated hydrophilic channel of the mitochondrial inner membrane by nucleotides. J. Membr. Biol. 1980, 54, 231-236. [CrossRef]

10. Bindoli, A.; Callegaro, M.T.; Barzon, E.; Benetti, M.; Rigobello, M.P. Influence of the redox state of pyridine nucleotides on mitochondrial sulfhydryl groups and permeability transition. Arch. Biochem. Biophys. 1997, 342, 22-28. [CrossRef]

11. Zago, E.B.; Castilho, R.F.; Vercesi, A.E. The redox state of endogenous pyridine nucleotides can determine both the degree of mitochondrial oxidative stress and the solute selectivity of the permeability transition pore. FEBS Lett. 2000, 478, 29-33. [CrossRef]

12. Sundaresan, N.R.; Gupta, M.; Kim, G.; Rajamohan, S.B.; Isbatan, A.; Gupta, M.P. Sirt3 blocks the cardiac hypertrophic response by augmenting Foxo3a-dependent antioxidant defense mechanisms in mice. J. Clin. Invest. 2009, 119, 2758-2771. [CrossRef]

13. Porter, G.A.; Urciuoli, W.R.; Brookes, P.S.; Nadtochiy, S.M. SIRT3 deficiency exacerbates ischemia-reperfusion injury: Implication for aged hearts. Am. J. Physiol. Heart. Circ. Physiol. 2014, 306, H1602-H1609. [CrossRef]

14. Tao, R.; Kim, S.H.; Honbo, N.; Karliner, J.S.; Alano, C.C. Minocycline protects cardiac myocytes against simulated ischemiareperfusion injury by inhibiting poly(ADP-ribose) polymerase-1. J. Cardiovasc. Pharmacol. 2010, 56, 659-668. [CrossRef]

15. Schriewer, J.M.; Peek, C.B.; Bass, J.; Schumacker, P.T. ROS-mediated PARP activity undermines mitochondrial function after permeability transition pore opening during myocardial ischemia-reperfusion. J. Am. Heart Assoc. 2013, 2, 159. [CrossRef]

16. Kahraman, S.; Siegel, A.; Polster, B.M.; Fiskum, G. Permeability transition pore-dependent and PARP-mediated depletion of neuronal pyridine nucleotides during anoxia and glucose deprivation. J. Bioenerg Biomembr. 2015, 47, 53-61. [CrossRef] [PubMed]

17. Zhang, M.; Ying, W. NAD(+) Deficiency is a common central pathological factor of a number of diseases and aging: Mechanisms and therapeutic implications. Antioxid. Redox Signal. 2019, 30, 890-905. [CrossRef]

18. Lee, C.F.; Chavez, J.D.; Garcia-Menendez, L.; Choi, Y.; Roe, N.D.; Chiao, Y.A.; Edgar, J.S.; Goo, Y.A.; Goodlett, D.R.; Bruce, J.E.; et al. Normalization of NAD+ redox balance as a therapy for heart failure. Circulation 2016, 134, 883-894. [CrossRef] [PubMed]

19. Kristian, T.; Balan, I.; Schuh, R.; Onken, M. Mitochondrial dysfunction and nicotinamide dinucleotide catabolism as mechanisms of cell death and promising targets for neuroprotection. J. Neurosci. Res. 2011, 891, 946-1955. [CrossRef]

20. Kruglov, A.G.; Teplova, V.V.; Saris, N.E. The effect of the lipophilic cation lucigenin on mitochondria depends on the site of its reduction. Biochem. Pharmacol. 2007, 74, 545-556. [CrossRef] [PubMed]

21. Kruglov, A.G.; Subbotina, K.B.; Saris, N.E. Redox-cycling compounds can cause the permeabilization of mitochondrial membranes by mechanisms other than ROS production. Free Radic. Biol. Med. 2008, 44, 646-656. [CrossRef]

22. Nikiforova, A.B.; Saris, N.E.; Kruglov, A.G. External mitochondrial NADH-dependent reductase of redox cyclers: VDAC1 or Cyb5R3? Free Radic. Biol. Med. 2014, 74, 74-84. [CrossRef] [PubMed]

23. Kharechkina, E.S.; Nikiforova, A.B.; Teplova, V.V.; Odinokova, I.V.; Krestinina, O.V.; Baburina, Y.L.; Kruglova, S.A.; Kruglov, A.G. Regulation of permeability transition pore opening in mitochondria by external NAD(H). Biochim. Biophys. Acta Gen. Subj. 2019, 1863, 771-783. [CrossRef] [PubMed]

24. Stein, L.R.; Imai, S. The dynamic regulation of NAD metabolism in mitochondria. Trends Endocrinol. Metab. 2012, 23, 420-428. [CrossRef] [PubMed] 
25. Barile, M.; Passarella, S.; Danese, G.; Quagliariello, E. Rat liver mitochondria can synthesize nicotinamide adenine dinucleotide from nicotinamide mononucleotide and ATP via a putative matrix nicotinamide mononucleotide adenylyltransferase. Biochem. Mol. Biol. Int. 1996, 38, 297-306. [PubMed]

26. Al-Nasser, I.; Crompton, M. The reversible Ca2+-induced permeabilization of rat liver mitochondria. Biochem. J. 1986, 239, 19-29. [CrossRef]

27. Broekemeier, K.M.; Schmid, P.C.; Schmid, H.H.; Pfeiffer, D.R. Effects of phospholipase A2 inhibitors on ruthenium red-induced Ca2+ release from mitochondria. J. Biol. Chem. 1985, 260, 105-113. [CrossRef]

28. Novgorodov, S.A.; Gudz, T.I.; Milgrom, Y.M.; Brierley, G.P. The permeability transition in heart mitochondria is regulated synergistically by ADP and cyclosporin A. J. Biol. Chem. 1992, 267, 16262-16274. [CrossRef]

29. Broekemeier, K.M.; Klocek, C.K.; Pfeiffer, D.R. Proton selective substate of the mitochondrial permeability transition pore: Regulation by the redox state of the electron transport chain. Biochemistry 1998, 37, 13059-13065. [CrossRef]

30. Kharechkina, E.S.; Nikiforova, A.B.; Kruglov, A.G. Pyridine nucleotides regulate the superoxide anion flash upon permeabilization of mitochondrial membranes: An MCLA-based study. Free Radic. Biol. Med. 2018, 124, 473-483. [CrossRef] [PubMed]

31. Belosludtsev, K.N.; Dubinin, M.V.; Belosludtseva, N.V.; Mironova, G.D. Mitochondrial Ca2+ Transport: Mechanisms, Molecular Structures, and Role in Cells. Biochemistry 2019, 84, 593-607. [CrossRef]

32. Rostovtseva, T.K.; Komarov, A.; Bezrukov, S.M.; Colombini, M. Dynamics of nucleotides in VDAC channels: Structure-specific noise generation. Biophys. J. 2002, 82, 193-205. [CrossRef]

33. Szabo, I.; Bernardi, P.; Zoratti, M. Modulation of the mitochondrial megachannel by divalent cations and protons. J. Biol. Chem. 1992, 267, 2940-2946. [CrossRef]

34. Hüser, J.; Rechenmacher, C.E.; Blatter, L.A. Imaging the permeability pore transition in single mitochondria. Biophys. J. 1998, 74, 2129-2137. [CrossRef]

35. Hüser, J.; Blatter, L.A. Fluctuations in mitochondrial membrane potential caused by repetitive gating of the permeability transition pore. Biochem J. 1999, 343, 311-317. [CrossRef] [PubMed]

36. Vergun, O.; Votyakova, T.V.; Reynolds, I.J. Spontaneous Changes in Mitochondrial Membrane Potential in Single Isolated Brain Mitochondria. Biophys. J. 2003, 85, 3358-3366. [CrossRef]

37. Lu, X.; Kwong, J.Q.; Molkentin, J.D.; Bers, D.M. Individual Cardiac Mitochondria Undergo Rare Transient Permeability Transition Pore Openings. Circ. Res. 2016, 118, 834-841. [CrossRef]

38. Chernyak, B.V.; Bernardi, P. The mitochondrial permeability transition pore is modulated by oxidative agents through both pyridine nucleotides and glutathione at two separate sites. Eur. J. Biochem. 1996, 238, 623-630. [CrossRef]

39. Nieminen, A.L.; Byrne, A.M.; Herman, B.; Lemasters, J.J. Mitochondrial permeability transition in hepatocytes induced by t-BuOOH: NAD(P)H and reactive oxygen species. Am. J. Physiol. 1997, 272, 1286-1294. [CrossRef]

40. Busanello, E.N.B.; Figueira, T.R.; Marques, A.C.; Navarro, C.D.C.; Oliveira, H.C.F.; Vercesi, A.E. Facilitation of Ca2+-induced opening of the mitochondrial permeability transition pore either by nicotinamide nucleotide transhydrogenase deficiency or statins treatment. Cell Biol. Int. 2018, 42, 742-746. [CrossRef] [PubMed]

41. Nightigale, E.R. Phenomenological theory of ion solvation. Effective radii of hydrated ions. J. Phys. Chem. 1959, 63, 1381-1387. [CrossRef]

42. Schultz, S.G.; Solomon, A.K. Determination of the Effective Hydrodynamic Radii of Small Molecules by Viscometry. J. Gen. Phys. 1961, 44, 1189-1199. [CrossRef]

43. Broekemeier, K.M.; Pfeiffer, D.R. Inhibition of the mitochondrial permeability transition by cyclosporin A during long time frame experiments: Relationship between pore opening and the activity of mitochondrial phospholipases. Biochemistry 1995, 34, 16440-16449. [CrossRef] [PubMed]

44. Schlegel, J.; Schweizer, M.; Richter, C. "Pore" formation is not required for the hydroperoxide-induced Ca2+ release from rat liver mitochondria. Biochem. J. 1992, 285, 65-69. [CrossRef] [PubMed]

45. Kushnareva, Y.E.; Sokolove, P.M. Prooxidants open both the mitochondrial permeability transition pore and a low conductance channel in the inner mitochondrial membrane. Arch. Biochem. Biophys. 2000, 376, 377-388. [CrossRef] [PubMed]

46. Toninello, A.; Salvi, M.; Schweizer, M.; Richter, C. Menadione induces a low conductance state of the mitochondrial inner membrane sensitive to bongkrekic acid. Free Radic Biol Med. 2004, 37, 1073-1080. [CrossRef]

47. Brierley, G.P.; Baysal, K.; Jung, D.W. Cation transport systems in mitochondria: Na+ and K+ uniports and exchangers. J. Bioenerg Biomembr. 1994, 26, 519-526. [CrossRef]

48. Li, X.; Weinman, S.A. Chloride channels and hepatocellular function: Prospects for molecular identification. Annu. Rev. Physiol. 2002, 64, 609-633. [CrossRef]

49. Drummond-Main, C.D.; Rho, J.M. Electrophysiological characterization of a mitochondrial inner membrane chloride channel in rat brain. FEBS Lett. 2018, 592, 1545-1553. [CrossRef]

50. Bernardi, P. Mitochondrial transport of cations: Channels, exchangers, and permeability transition. Physiol. Rev. 1999, 79, 1127-1155. [CrossRef] [PubMed]

51. Lee, A.C.; Zizi, M.; Colombini, M. Beta-NADH decreases the permeability of the mitochondrial outer membrane to ADP by a factor of 6. J. Biol. Chem. 1994, 269, 30974-30980. [CrossRef]

52. Lee, A.C.; Xu, X.; Colombini, M. The role of pyridine dinucleotides in regulating the permeability of the mitochondrial outer membrane. J. Biol. Chem. 1996, 271, 26724-26731. [CrossRef] 
53. Han, D.; Antunes, F.; Canali, R.; Rettori, D.; Cadenas, E. Voltage-dependent anion channels control the release of the superoxide anion from mitochondria to cytosol. J. Biol. Chem. 2003, 278, 5557-5563. [CrossRef] [PubMed]

54. Lustgarten, M.S.; Bhattacharya, A.; Muller, F.L.; Jang, Y.C.; Shimizu, T.; Shirasawa, T.; Richardson, A.; Van Remmen, H. Complex I generated, mitochondrial matrix-directed superoxide is released from the mitochondria through voltage dependent anion channels. Biochem. Biophys. Res. Commun. 2012, 422, 515-521. [CrossRef] [PubMed]

55. Villinger, S.; Giller, K.; Bayrhuber, M.; Lange, A.; Griesinger, C.; Becker, S.; Zweckstetter, M. Nucleotide interactions of the human voltage-dependent anion channel. J. Biol. Chem. 2014, 289, 13397-13406. [CrossRef] [PubMed]

56. Chinopoulos, C. Mitochondrial permeability transition pore: Back to the drawing board. Neurochem. Int. 2018, 117, 49-54. [CrossRef]

57. Tarze, A.; Deniaud, A.; Le Bras, M.; Maillier, E.; Molle, D.; Larochette, N.; Zamzami, N.; Jan, G.; Kroemer, G.; Brenner, C. GAPDH, a novel regulator of the pro-apoptotic mitochondrial membrane permeabilization. Oncogene 2007, 26, 2606-2620. [CrossRef]

58. Allouche, M.; Pertuiset, C.; Robert, J.L.; Martel, C.; Veneziano, R.; Henry, C.; dein, O.S.; NSaint Brenner, C.; Chopineau, J. ANT-VDAC1 interaction is direct and depends on ANT isoform conformation in vitro. Biochem. Biophys. Res. Commun. 2012, 429, 12-17. [CrossRef]

59. Vyssokikh, M.; Brdiczka, D. VDAC and peripheral channelling complexes in health and disease. Mol. Cell. Biochem. 2004, 256-257, 117-126. [CrossRef] [PubMed]

60. Anflous-Pharayra, K.; Cai, Z.J.; Craigen, W.J. VDAC1 serves as a mitochondrial binding site for hexokinase in oxidative muscles. Biochim. Biophys. Acta. 2007, 1767, 136-142. [CrossRef] [PubMed]

61. Abu-Hamad, S.; Zaid, H.; Israelson, A.; Nahon, E.; Shoshan-Barmatz, V. Hexokinase-I protection against apoptotic cell death is mediated via interaction with the voltage-dependent anion channel-1: Mapping the site of binding. J. Biol. Chem. 2008, 283, 13482-13490. [CrossRef]

62. Johnson, D.; Lardy, H. Isolation of liver or kidney mitochondria. Methods Enzymol. 1967, 10, $94-96$.

63. Krestinina, O.; Azarashvili, T.; Baburina, Y.; Galvita, A.; Grachev, D.; Stricker, R.; Reiser, G. In aging, the vulnerability of rat brain mitochondria is enhanced due to reduced level of $2^{\prime}, 3^{\prime}$-cyclic nucleotide- $3^{\prime}$-phosphodiesterase (CNP) and subsequently increased permeability transition in brain mitochondria in old animals. Neurochem. Int. 2015, 80, 41-50. [CrossRef] [PubMed]

64. Gornall, A.G.; Bardawill, C.J.; David, M.M. Determination of serum proteins by means of the biuret reaction. J. Biol. Chem. 1949, 177, 751-766. [CrossRef]

65. Herman, B.; Nieminen, A.L.; Gores, G.J.; Lemasters, J.J. Irreversible injury in anoxic hepatocytes precipitated by an abrupt increase in plasma membrane permeability. FASEB J. 1988, 2, 146-151. [CrossRef] [PubMed] 